
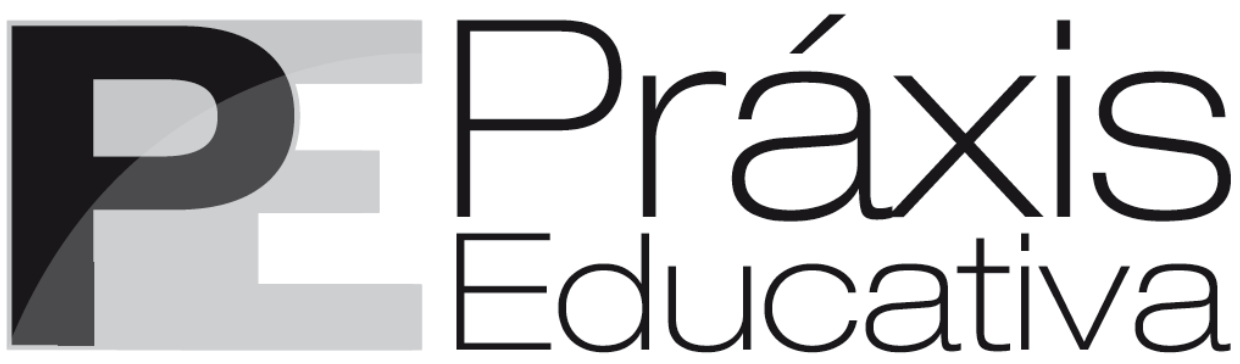

ISSN 1809-4309 (Versão online) DOI: 10.5212/PraxEduc.v.12i3.005

\title{
A produção do conhecimento em educação: o Pós-estruturalismo como potência epistemológica*
}

\section{Knowledge production in education: Post-structuralism as epistemological potency}

\section{La producción del conocimiento en la educación: el Posestructuralismo como potencia epistemológica}

Sirley Lizott Tedeschi** Ruth Pavan ${ }^{* * *}$

\begin{abstract}
Resumo: $O$ presente artigo tem como objetivo analisar as potencialidades epistemológicas e metodológicas do Pós-estruturalismo na pesquisa em educação. De caráter teórico-bibliográfico, a pesquisa toma como principais referências as contribuições de Michel Foucault, Gilles Deleuze e Jacques Derrida para problematizar as metanarrativas modernas e os processos de produção do conhecimento nessa área. Ao problematizar as metanarrativas modernas e expor o caráter histórico, contextual, inerente ao processo de construção do conhecimento, essa perspectiva epistemológica tem provocado uma série de inquietações, de dúvidas, de descontinuidades que repercutem nos processos investigativos na área. Abrir-se para esse campo epistemológico pode contribuir para uma desconstrução do aparato conceitual da modernidade, que tanto tem marcado a pesquisa em educação, e abrir outras possibilidades epistemológicas e metodológicas para a produção do conhecimento nessa área. Nesse sentido, a potencialidade dessa perspectiva epistemológica e metodológica para a pesquisa em educação está na multiplicidade de possibilidades que ela proporciona.
\end{abstract}

Palavras-chave: Pesquisa. Educação. Pós-estruturalismo.

\begin{abstract}
This paper aims to analyze the epistemological and methodological potentialities of Poststructuralism in education research. With a theoretical-bibliographic character, the research takes as main references Michel Foucault, Gilles Deleuze and Jacques Derrida's contributions in order to problematize the modern metanarratives and the processes of knowledge production in this area. By problematizing modern metanarratives and pointing out the historical, contextual character, inherent in the process of knowledge production, this epistemological perspective has triggered a number of concerns, doubts and discontinuities that have reverberated in investigative processes in that area. Being open to this epistemological field may both contribute to the deconstruction of the conceptual apparatus of modernity,

\footnotetext{
* Esta pesquisa foi financiada pela Coordenação de Aperfeiçoamento de Pessoal de Nível Superior (CAPES/OBEDUC).

** Professora da Universidade Estadual de Mato Grosso do Sul (UEMS). E-mail: <tedeschils@gmail.com>.

*** Professora da Universidade Católica Dom Bosco (UCDB). E-mail: <ruth@ucdb.br>.
} 
which has strongly marked the education research, and bring other epistemological and methodological possibilities for knowledge production in that area. In this sense, the potentiality of this epistemological and methodological perspective for research in education is the multiplicity of possibilities that it provides. Keywords: Research. Education. Post-structuralism.

Resumen: El presente artículo tiene como objetivo analizar las potencialidades epistemológicas y metodológicas del posestructuralismo en la investigación en la educación. Esta investigación, de carácter teórico-bibliográfico, toma como principales referencias a las contribuciones de Michael Foucault, Guilles Deleuze y Jacques Derrida para problematizar las metanarrativas modernas y los procesos de producción del conocimiento en el área. Al problematizar las metanarrativas modernas y exponer el carácter histórico, contextual, inherente al proceso de construcción del conocimiento, esta perspectiva epistemológica ha provocado una serie de inquietudes, de dudas, de discontinuidades que repercuten en los procesos de investigación en el área. Abrirse al campo epistemológico puede contribuir para una desconstrucción del aparato conceptual de la modernidad, que tanto ha marcado la pesquisa en la educación, y abrir otras posibilidades epistemológicas y metodológicas para la producción del conocimiento en el área. En este sentido, la potencialidad de esta perspectiva epistemológica y metodológica para la investigación en la educación está en la multiplicidad de posibilidades que ella proporciona.

Palabras clave: Investigación. Educación. Posestructuralismo.

\section{Introdução}

A presença de teóricos pós-estruturalistas - como Michel Foucault, Gilles Deleuze e Jacques Derrida - nas pesquisas em educação é inegável, e suas reflexões têm possibilitado rever os aparatos conceituais e metodológicos da modernidade que tanto têm marcado a pesquisa nessa área. Como perspectiva epistemológica e metodológica, o Pós-estruturalismo tem produzido uma série de inquietações, de dúvidas, de contribuições; tem mobilizado o pensamento educacional e viabilizado re/significar os sentidos e os usos de metodologias nos processos de investigação.

O fato de o Pós-estruturalismo não definir a priori um método para as pesquisas e desafiar os pesquisadores a construí-lo no decorrer do processo implica um afastamento da Modernidade e de sua aposta em um unitarismo epistemológico ou perspectiva privilegiada capaz de compreender como o mundo é e como funciona. Afinal, o Pós-estruturalismo parte da perspectiva de que as metodologias devem ser construídas no percurso da investigação, de acordo com o objeto de pesquisa e as questões elaboradas e suscitadas, pois não é possível estabelecer antecipadamente os passos ou procedimentos denominados metodológicos e construir caminhos em abstrato ou modelos prévios. Em outras palavras, a perspectiva pósestruturalista entende que não se pode estabelecer de antemão o processo de pesquisa, pois nada assegura que o planejado a priori se concretize ou que postulações teóricas previamente estabelecidas funcionem.

Nesse sentido, o método pode ser entendido "[...] como uma certa forma de interrogação e um conjunto de estratégias analíticas de descrição" (LARROSA, 2011, p. 37), “[...] como um conjunto de procedimentos de investigação e análise quase prazerosos, sem maiores preocupações com regras práticas aplicáveis a problemas técnicos, concretos" (VEIGA-NETO, 2003, p. 20). Trata-se de um entendimento metodológico relacionado a certo modo de elaborar perguntas e interrogações, de articulá-las com a produção de informações e de encontrar mecanismos ou estratégias de descrição e análise.

A partir dessa perspectiva epistemológica, da impossibilidade de apreender o real da forma como pretendia a modernidade, buscamos, em nossas pesquisas, possibilidades de contextualizar, analisar, problematizar, modificar verdades singulares e contextuais, pois "[...] 
contestar um discurso, desqualificar enunciados, pode ajudar a derrubar o dispositivo que os apoia" (VEYNE, 2009, p. 104). O conhecimento que produzimos no processo de nossas investigações é, desde sempre, conhecimento interessado tanto epistemologicamente quanto politicamente, visto que "[...] o que vale como verdade é objeto de disputa, vai ser determinado na luta" (MEYER, 2012, p. 54), e nossas pesquisas estão inseridas nesse processo de disputa por produção de verdades.

Enquanto o método, entendido na perspectiva moderna, indica o caminho da pesquisa, regrado por princípios fixados de antemão e se empenha, conforme Foucault (2000), em buscar a essência exata das coisas, sua possibilidade primeira, sua identidade fechada em si mesma, sua forma imóvel e anterior a tudo o que é externo e acidental, o Pós-estruturalismo aproxima-se da pesquisa genealógica. Dreyfus e Rabinow (2013), ao referirem-se à genealogia foucaultiana, afirmam que a genealogia se opõe ao método histórico tradicional e que seu objetivo é mostrar a singularidade dos acontecimentos. Para a genealogia:

[...] não há essências fixas, nem leis subjacentes, nem finalidades metafísicas. A genealogia busca descontinuidades ali onde desenvolvimentos contínuos foram encontrados. Ela busca recorrências e jogos ali onde progresso e seriedade foram encontrados. Ela recorda o passado da humanidade para desmascarar os hinos solenes do progresso. A genealogia evita a busca da profundidade. Ela busca a superfície dos acontecimentos, os mínimos detalhes, as menores mudanças e os contornos sutis. (DREYFUS; RABINOW, 2013, p. 142).

A genealogia, nessa perspectiva, propõe-se a escutar a história, considerando seus acasos e descontinuidades para aprender “[...] que atrás das coisas há algo inteiramente diferente: não seu segredo essencial e sem data, mas o segredo que elas são sem essência ou que sua essência foi construída peça por peça a partir de figuras que lhe eram estranhas" (FOUCAULT, 2000, p. 18). Mesmo a razão, diz Foucault (2000), nasceu do acaso, da paixão dos cientistas, da vontade de verdade e da necessidade de superar as paixões. Trata-se de pesquisar em educação, não para avaliar o passado em nome de uma nova verdade - pois não existe nenhuma identidade preservada -, mas para analisar o que somos, enquanto enredados pela vontade de verdade. Ainda, trata-se de uma pesquisa que busca liberar os saberes históricos - razão, verdade, sujeito -, torná-los capazes, como diz Foucault (2000), de oposição e de luta contra a coerção de um discurso que se pretende unitário, formal, científico, verdadeiro.

Pimenta (2000), com esteio nas ideias nietzschianas, diz que podemos pensar a diferença entre a pesquisa genealógica e a perspectiva moderna de método como a diferença entre " [...] a excursão de um andarilho por um terreno a um tempo estranho e familiar - imagem cara a Nietzsche - e uma expedição científica voltada para a comprovação de um corpo de postulações teóricas previamente estabelecidas" (PIMENTA, 2000, p. 80). Enquanto o excursionista passeia sem princípios rígidos e acolhe sua experiência a partir de várias perspectivas, a expedição científica só é capaz de reconhecer indícios que coincidam com aquilo que desejava demonstrar desde o início. Por isso, entendemos o fato de teóricos como Friedrich W. Nietzsche, Michel Foucault e Gilles Deleuze não pretenderem elaborar um modelo teórico e metodológico para ninguém. No entanto, isso não significa negar a utilização, em nossas pesquisas, de práticas e de procedimentos de que já dispomos; o que não se quer é ficar preso a esses princípios.

Tendo isso em vista, apresentamos a seguir posicionamentos epistemológicos e elementos conceituais que consideramos importantes quando assumimos a perspectiva pós-estruturalista para a pesquisa em educação - eles nos mostram o que é preciso levar em consideração na construção dos modos de interrogar adequados nessa perspectiva. 


\section{As potencialidades epistemológicas e analíticas do Pós-estruturalismo na pesquisa em educação}

O Pós-estruturalismo, como abordagem epistemológica, pode ser caracterizado como "[...] um modo de pensamento, um estilo de filosofar e uma forma de escrita, embora o termo não deva ser utilizado para dar qualquer ideia de homogeneidade, singularidade ou unidade" (PETERS, 2000, p. 28). Por isso, o Pós-estruturalismo não pode ser reduzido a um método, a uma teoria ou até mesmo a uma escola; “[...] é melhor referir-se a ele como um movimento de pensamento - uma complexa rede de pensamento - que corporifica diferentes formas de prática crítica" (PETERS, 2000, p. 29). Tem como referência autores franceses - como Jacques Derrida, Michel Foucault e Gilles Deleuze - e representa uma crítica ao humanismo, ao sujeito racional e autônomo, às pretensões universais da razão, ao cientificismo das ciências humanas. Por isso, também assume uma epistemologia antifundacionalista e perspectivista. Desse modo, o Pósestruturalismo afasta-se dos pressupostos modernos de universalidade, unidade e identidade, assumindo a diferença como categoria importante em seu pensamento.

A diferença é um tema constante na obra de Gilles Deleuze, pensador que contribui para o desenvolvimento do Pós-estruturalismo. Em Diferença e Repetição, Deleuze (1988) propõe-se a pensar a diferença indo além da filosofia da representação, que a mantinha presa ao princípio de identidade. De acordo com o autor, atrelada ao princípio de identidade, a diferença sempre foi apresentada como negação do ser ou como um conceito de uma potência derivada. No pensamento deleuziano, a diferença libera toda a sua força e coloca-se como potência primeira. Deleuze (1976) destaca, na obra Nietzsche e a filosofia, que Nietzsche também foi fundamental para o surgimento de uma filosofia da diferença e interpreta sua filosofia como uma crítica à dialética de Hegel, entendida "[...] como uma força esgotada que não tem força para afirmar sua diferença" (DELEUZE, 1976, p. 7). Trata-se de uma dialética que nega tudo que não é ela mesma e que faz dessa negação a sua própria essência e o princípio de sua existência. No lugar da negação, da oposição e da contradição, Nietzsche coloca a diferença como elemento de afirmação, como "[...] o prazer de se saber diferente, o gozo da diferença” (DELEUZE, 1976, p. 7). Desse modo, a diferença é uma categoria central para o Pós-estruturalismo e possibilita descentrar a força das metanarrativas modernas, abrindo espaços para enfatizar as multiplicidades por meio da indeterminação e do jogo da diferença.

Então, assumir o Pós-estruturalismo como perspectiva epistemológica e metodológica para a pesquisa em educação implica a desconstrução de metanarrativas construídas na modernidade que marcam a produção do conhecimento nessa área. Deleuze, Derrida, Foucault, entre outros, problematizam todos os valores transcendentes que pretendem uma independência ante as lutas e valorações históricas que os engendram. Categorias modernas, como razão, verdade, discurso, poder, identidade e diferença, têm sido desestabilizadas pela crítica pósestruturalista. A própria temática do sujeito só é pertinente para Foucault (2002) na medida em que considera o problema de sua constituição histórica. Trata-se de uma aposta na historicidade do dizer a verdade e na rejeição de qualquer transcendência ou transcendentalidade. Nesse caso, a pretensão não é elaborar uma teoria da verdade; pelo contrário, é fazer uma crítica do dizer a verdade.

Ao colocarem sob suspeita as categorias modernas, em sua ambição universalista, esses teóricos produziram/produzem efeitos na forma como temos interrogado e conduzido os processos de investigação em educação, ou seja, abrem outras possibilidades e potencialidades epistemológicas. Paraíso (2012) diz que o que esses teóricos “[...] desconstruíram do pensamento moderno e alguns dos conceitos que criaram ou com os quais operaram" (PARAÍSO, 2012, p. 25) passaram a constituir, de certa forma, algumas re/significações para o desenvolvimento da 
pesquisa nessa área. Nesse sentido, apresentamos a seguir algumas dessas re/significações, pois as consideramos importantes quando assumimos o Pós-estruturalismo como abordagem epistemológica e metodológica para a construção do conhecimento no campo educacional.

a) Destacamos a necessidade de desconstrução dos sistemas universais da razão que visam, por meio do homem racional, indicar o caminho do desenvolvimento, do progresso e, em decorrência, do bem-estar humano. Entendemos com Derrida e Roudinesco (2004) que desconstruir não significa negar os valores dados como universais pela filosofia ocidental; antes, trata-se de abalar o alicerce que sustenta o que já foi pensado pelo homem, posto em prática e tornado hegemônico. Na obra De que amanhã... diálogo, esses autores procuram mostrar que a "desconstrução" não significa destruição, mas sim uma forma de proceder que busca desorganizar, desmantelar os discursos empreendidos pela metafísica para dar-lhes diferentes funcionamentos. Nas palavras de Derrida e Roudinesco (2004), desconstrução significa

[...] a deposição ou decomposição de uma estrutura. Em sua definição derridiana, remete a um trabalho do pensamento inconsciente ("isso se desconstrói”), e que consiste em desfazer, sem nunca destruir um sistema de pensamento hegemônico ou dominante. Desconstruir é de certo modo resistir à tirania do Um, do logos da metafísica (ocidental) na própria língua que é enunciada, com a ajuda do próprio material deslocado, movido com fins de reconstruções cambiantes. (DERRIDA; ROUDINESCO, 2004, p. 9, grifos dos autores).

Partindo do pensamento derridiano, Santiago (1995) diz que, abalado o alicerce do discurso metafísico ocidental pelo efeito da leitura desconstrutora, cabe analisá-lo com a intenção "[...] de enxergar o que ele escondeu, escamoteou e recalcou, para possibilitar que, em cima do escondido, do escamoteado e do recalcado, [...] se construísse o belo edifício sólido, justo por um lado e injusto por outro, das categorias universais" (SANTIAGO, 1995, p. 101). Por isso, quando operamos em nossas pesquisas com a leitura desconstrutora das categorias que foram fixadas, naturalizadas e universalizadas - como é o caso da verdade, do discurso, do sujeito, do poder, das identidades e das diferenças -, abrimos possibilidades de produzir e incentivar a diferença, a invenção de outros significados e/ou de outras imagens de pensamento. Abrimos possibilidades de visibilizar o que foi invisibilizado pelo discurso hegemônico. A desconstrução, nesse caso, age no interior dos discursos educacionais hegemônicos, que, em certa medida, ainda sustentam o pensamento moderno ocidental, como uma forma de interrogá-los, de desestabilizá-los e, por conseguinte, de ampliar seus limites, ampliar as possibilidades de pensar os processos educacionais.

b) Desconstruir os sistemas universais da razão permite-nos pensar que o lugar onde se começa, seja ele qual for, é sempre “[...] sobredeterminado por estruturas históricas, políticas, filosóficas, fantasiosas, que não podemos por princípio jamais explicitar totalmente, nem controlar" (BENNINGTON; DERRIDA, 1996, p. 23). Na obra Foucault, o pensamento, a pessoa, Veyne (2009) diz que pensamos sempre dentro das fronteiras do discurso do momento presente, portanto não podemos pensar qualquer coisa a qualquer momento. De acordo com o autor, "[...] estamos sempre presos num aquário de cujas paredes nem nos apercebemos" (VEYNE, 2009, p. 32). Assim sendo, não podemos jamais ter a pretensão de alcançar a verdade, nem presente, nem futura. Afinal, as verdades não são naturais, mas sim históricas e, portanto, envolvidas em relações de poder e saber.

Por isso, entendemos que tudo tem uma história; que a própria história é uma construção decorrente de determinadas interpretações e relações de poder; que podemos desconstruir as evidências naturalizadas mostrando como foram produzidas, pois, se algo não foi sempre assim, nada determina que assim permaneça. Então, admitindo-se o caráter de construção das categorias modernas, como razão universal e sujeito único - que tanto influenciaram e ainda influenciam os 
processos educacionais -, é possível analisar o que essas verdades visibilizam e invisibilizam, o que convocam e silenciam. Dessa forma, podemos criar, em uma linguagem foucaultiana, "fraturas do presente", criar um vazio de significados que se abrem para a possibilidade de $\mathrm{re} /$ significações em educação.

c) Acreditando na historicidade do dizer a verdade e afastando-nos de todas as grandes verdades atemporais, pensamos com Foucault (2000, 1996a, 1988, 2005) que a verdade é fabricada social e institucionalmente, que não existe a "verdade", mas "regimes de verdade". De acordo com o autor, cada sociedade possui seu regime de verdade, sua política geral de verdade; cada sociedade possui determinados discursos que aceita e faz funcionar como verdadeiros; ou, nas palavras do autor, cada sociedade possui os mecanismos e instâncias que permitem "[...] distinguir entre sentenças verdadeiras e falsas, os meios pelos quais cada um deles é sancionado; as técnicas e procedimentos valorizados na aquisição da verdade; o status daqueles que estão encarregados de dizer o que conta como verdadeiro" (FOUCAULT, 2000, p. 12).

Como regime de verdade, os discursos com base na racionalidade moderna, científica, em certa medida, ainda têm tido primazia nos processos educacionais e têm se encarregado de dizer o que é verdadeiro e o que é falso em educação. Embora discursos alternativos também circulem nessas instituições educacionais, como micropolíticas, funcionam no contexto da política de verdade dominante. Por isso, para Foucault (1996b), aquilo que convencionamos chamar de verdade representa a justificação racional de sistemas excludentes de poder presentes em diversas instituições - como hospitais, prisões e escolas.

[...] se nos situarmos no nível de uma proposição, no interior de um discurso, a separação entre o verdadeiro e o falso não é nem arbitrária, nem modificável, nem institucional, nem violenta. Mas se nos situarmos em outra escala, se levantamos a questão de saber qual foi, qual é constantemente, através de nossos discursos, essa vontade de verdade que atravessou tantos séculos de nossa história, ou qual é, em sua forma muito geral, o tipo de separação que rege nossa vontade de saber, então é talvez algo como um sistema de exclusão (sistema histórico institucionalmente constrangedor) que vemos desenhar-se. (FOUCAULT, 1996b, p. 14).

Nesse sentido, "[...] o discurso qualificado como verdadeiro é aquele que se impôs sobre outros discursos, relegando-os ao terreno do falso e do ilusório, instaurando assim uma ordem" (CANDIOTTO, 2010, p. 51) que determina o que é verdadeiro e falso. Isso nos faz compreender que o discurso não é neutro e não reproduz algo que já está constituído; pelo contrário, é um campo estratégico de enfrentamento, controle e poder - espaço de articulação de forças que qualifica ou desqualifica os saberes. Desse modo, pensamos com Paraíso (2012) que todos os discursos, inclusive os discursos que são objetos de nossas análises e os discursos que construímos como resultado de nossas pesquisas, são parte de uma luta para construir as próprias versões de verdade.

d) Entendemos o discurso como histórico porque se constrói em um tempo e espaço determinados e porque "[...] tem uma positividade concreta, investe-se em práticas, em instituições, em um número infindável de técnicas e procedimentos, que, em última análise, agem nos grupos sociais e nos indivíduos" (COLLING, 2014, p. 18). O discurso é, então, de acordo com Foucault (2005), constituído de práticas discursivas e não-discursivas que formam um dispositivo de saber-poder.

[...] gostaria de mostrar que o discurso não é uma estreita superfície de contato, ou de confronto, entre uma realidade e uma língua, o intrincamento entre um léxico e uma experiência; gostaria de mostrar, por meio de exemplos precisos, que, analisando os próprios discursos, vemos se desfazerem os laços aparentemente tão fortes entre as palavras e as coisas, e destacar-se um conjunto de regras, próprias da prática discursiva.

Práxis Educativa, Ponta Grossa, v. 12, n. 3, p. 772-787, set./dez. 2017 Disponível em: <http://www.revistas2.uepg.br/index.php/praxiseducativa $>$ 
[...] não mais tratar os discursos como conjunto de signos (elementos significantes que remetem a conteúdos ou a representações), mas como práticas que formam sistematicamente os objetos de que falam. Certamente os discursos são feitos de signos; mas o que fazem é mais que utilizar esses signos para designar coisas. É esse mais que os torna irredutíveis à língua e ao ato da fala. É esse mais que é preciso fazer aparecer e que é preciso descrever. (FOUCAULT, 2005, p. 55).

Isso nos leva a pensar na materialidade do discurso e no seu envolvimento em sistemas de relações materiais que o estruturam e o constituem. Além de referir aquilo que é dito, a materialidade do discurso refere-se àquilo que não é dito e que concerne a gestos, atitudes, comportamentos e organização do espaço. Então, quando o propósito for fazer a análise de um discurso, será preciso "[...] antes de tudo recusar as explicações unívocas, as fáceis explicações e igualmente a busca insistente do sentido último ou do sentido oculto das coisas" (FISCHER, 2001, p. 198), pois o discurso é prático, produtivo e inscrito em regulamentadas formas de poder e sujeito a múltiplas coerções. Em outras palavras, nossas pesquisas precisam encontrar estratégias de descrição e análise que nos possibilitem trabalhar com o discurso para mostrar os enunciados e as relações que ele coloca em funcionamento, ou seja, analisar os discursos como envoltos em relações de saber-poder e como produtores de significados, de práticas, de sujeitos, de identidades e de diferenças.

Em um texto escrito em 1968, intitulado Sobre a Arqueologia das Ciências: Resposta ao Círculo de Epistemologia, que compõe a obra Ditos e escritos II, Foucault (2015b) diz que analisar um discurso não significa tentar descobrir, redescobrir, indo além dos próprios enunciados, a intenção do sujeito falante, sua atividade consciente, o que ele quis dizer. Para o autor, a análise do discurso tem uma finalidade completamente diferente; trata-se de compreender o enunciado na singularidade de seu acontecimento; de "[...] determinar as condições de sua existência, de fixar da maneira mais justa os seus limites, de estabelecer suas correlações com os outros enunciados aos quais ele pode estar ligado, de mostrar que outras formas de enunciação ele exclui" (FOUCAULT, 2015b, p. 97). Na análise de um discurso, em nenhum momento, trata-se de procurar alguma coisa além do que é manifesto, “[...] o falatório em surdina de um outro discurso" (FOUCAULT, 2015b, p. 97).

Então, quando fazemos a análise de um discurso, temos de considerar sua irrupção histórica, sua emergência, sua constituição; temos que considerar, ainda, os enunciados, mas não como qualquer coisa dita, pois, segundo Veiga-Neto (2003), os enunciados não são cotidianos, são sempre mais raros, mais rarefeitos. Ou, como o próprio Foucault (2005) diz em sua obra Arqueologia do Saber, "[...] chamaremos de discurso um conjunto de enunciados, na medida em que se apóiem na mesma formação discursiva" (FOUCAULT, 2005, p. 132).

Assim sendo, em pesquisas pós-estruturalistas, o discurso não será entendido como afirmações individuais de sujeitos soberanos, mas sim como um conjunto de enunciações em um determinado contexto, analisadas como parte de um determinado discurso. Como efeito, o sujeito do discurso não é um sujeito absoluto - cogito cartesiano -, alguém que diz alguma coisa a partir de uma interioridade; trata-se antes de uma posição de sujeito diante de um determinado discurso. Por isso, já não cremos em um sujeito que preexiste às formações discursivas.

e) Consideramos que o sujeito não é constituinte, mas constituído, assim como o seu objeto, processo que Foucault $(2000,1996$ a , 1988, 2005) nomeou de subjetivação. O conceito de subjetivação na teoria foucaultiana "[...] serve para eliminar a metafísica, o dobrete empíricotranscendental que retira do sujeito constituído o fantasma de um sujeito soberano" (VEYNE, 2009, p. 110). Há quase três séculos, o pensamento filosófico ocidental “[...] postulava explícita ou implicitamente, o sujeito como fundamento, como núcleo central de todo conhecimento, como aquilo em que a partir de que a liberdade se revelava e a verdade podia explodir" 
(FOUCALT, 2002, p. 10). Ainda hoje, de certo modo, quando produzimos conhecimento, atemo-nos a esse sujeito epistêmico como ponto de origem de toda a possível verdade.

Foucault (2002) contrapõe-se à ideia de um sujeito preexistente às formações discursivas que pudesse ser o organizador e unificador do conhecimento e coloca em seu lugar diferentes formas de subjetividade, que substituem a noção de subjetividade soberana. Desconstruído o sujeito na sua essencialidade, coloca com veemência o problema de sua constituição. Para esse autor, é importante compreender como se construiu ao longo da história a ideia de um sujeito que não é dado definitivamente, "[...] que não é aquilo a partir do que a verdade se dá na história, mas de um sujeito que se constitui no interior mesmo da história, e que é a cada instante fundado e refundado pela história" (FOUCAULT, 2002, p. 10).

Por isso, para Foucault (2004), o sujeito não é dado a priori, nem é livre e autônomo como apresentado pela filosofia moderna -, mas é sempre pensado como efeito de múltiplas e horizontais relações de poder e saber que o caracterizam como assujeitado e disciplinado. Não há um sujeito soberano, fundador, universal, que poderíamos encontrar em qualquer tempo e lugar. Foucault (2004) diz ser muito cético e hostil em relação a essa concepção do sujeito e pensa, pelo contrário, "[...] que o sujeito se constitui através das práticas de sujeição ou, de maneira mais autônoma, através de práticas de libertação, [...] a partir de um certo número de regras, de estilos, de convenções que podemos encontrar no meio cultural" (FOUCAULT, 2004, p. 291). Por esse motivo, depois de ter apresentado em Vigiar e Punir como se fabrica o indivíduo moderno efeito e instrumento de relações de poder e dispositivos de normalização -, Foucault adverte-nos de que "[...] temos que ouvir o ronco surdo da batalha" (FOUCAULT, 1996a, p. 269), o que leva a pensar que, mesmo em uma sociedade normalizadora, a resistência a práticas disciplinares e biopolíticas é sempre possível.

Então, quando em nossas pesquisas o propósito é fazer a análise de um discurso, não nos colocamos frente à manifestação de um sujeito; em vez disso, defrontamo-nos " [...] com um lugar de sua dispersão e descontinuidade, já que o sujeito da linguagem não é um sujeito em si, idealizado, essencial, origem inarredável do sentido: ele é ao mesmo tempo falante e falado" (FISCHER, 2001, p. 207). Em nossas pesquisas, procuramos entender o sujeito como forjado em cada época pelos dispositivos de saber/poder; procuramos entender aquilo que dá nome ao sujeito, que hierarquiza, disciplina, normaliza, governa e, por conseguinte, produz determinado tipo de sujeito.

f) Pensamos com Foucault (2000, 1996a, 1988, 2005) que o poder não pode ser reduzido aos aparelhos estatais, pois está em toda a parte e é por todos compartilhado. O autor reconhece o caráter difuso do poder e entende-o como conjuntos de relações de forças que agem de forma multidirecional e atingem todos os indivíduos. Por isso, empenha-se em construir uma análise ascendente de poder, partindo dos "[...] mecanismos infinitesimais que têm uma história, um caminho, técnicas e táticas e depois examina como esses mecanismos de poder foram e ainda são investidos [...] por mecanismos cada vez mais gerais" (FOUCAULT, 2000, p 184). Trata-se de uma análise que parte das microrrelações de poder para apropriar-se dos mecanismos e formas de abrangência mais gerais.

Entendido dessa forma, o "[...] poder mais se exerce do que se possui" (FOUCAULT, 1996a, p. 29); não é propriedade de uma classe ou indivíduo, transita por eles; não é um objeto definido e passível de ser identificado, localizado, manipulado e, por fim, nomeado; o poder é entendido em termos de relações de forças. Ainda, em si mesmo, o poder não existiria; o que existem são relações de poder, relações de força. $\mathrm{Na}$ obra Em defesa da sociedade, curso proferido no Collège de France (1975-1976), Foucault refere-se ao poder da seguinte maneira: 
[...] não tomar o poder como um fenômeno de dominação maciço e homogêneo dominação de um indivíduo sobre os outros, de um grupo sobre os outros, de uma classe sobre as outras; ter bem em mente que o poder, exceto ao considerá-lo de muito alto e de muito longe, não é algo que se partilhe entre aqueles que o têm e que o detêm exclusivamente, e aqueles que não o têm e que são submetidos a ele. $O$ poder, acho eu, deve ser analisado como uma coisa que circula, ou melhor como uma coisa que só funciona em cadeia. Jamais ele está localizado aqui ou ali, jamais está entre as mãos de alguns, jamais é apossado como uma riqueza e um bem. O poder funciona. O poder se exerce em rede e, nessa rede, não só os indivíduos circulam, mas estão sempre em posição de ser submetidos a esse poder e também de exercê-lo. Jamais eles são o alvo inerte ou consentidor do poder, são sempre seus intermediários. (FOUCAULT, 1999, p. 34-35).

Podemos dizer que a concepção de poder como relações de forças, conforme Foucault (1999) desenvolve, ao mesmo tempo que se afasta da ideia de um poder central que domina e reprime, ressalta a positividade do poder. O poder entendido como relações de força produz ideias, saberes, discursos, objetos e verdades a partir do contexto de cada indivíduo, o que garante sua ramificação e difusão. Daí não ser possível separar poder e saber nas análises foucaultianas, tornando-se necessário reforçar a ideia de que a "[...] implicação entre tais relações de poder e a produção de saberes não é mera aproximação de categorias distintas sem um vínculo de causalidade entre si, mas, ao contrário, tal implicação revela uma dependência mútua" (FONSECA, 2011, p. 35).

Contrariando as formas clássicas de conceber o saber e o poder, Foucault (1996a) descarta a possibilidade de que "[...] só pode haver saber onde as relações de poder estão suspensas e que o saber só pode desenvolver-se fora de suas injunções, suas exigências e seus interesses" (FOUCAULT, 1996a, p. 29). Para ele, é preciso entender que o poder produz saber; "[...] que saber e poder estão diretamente implicados; que não há relação de poder sem constituição correlata de um campo de saber, nem saber que não supunha e não constitua ao mesmo tempo relações de poder" (FOUCAULT, 1996a, p. 30). Disso decorre o questionamento das pedagogias que se sustentam na utopia de identificar as fontes e as origens do poder para transcender seu caráter necessariamente regulativo e de controle.

g) Não havendo um lugar central onde o poder se manifesta, também não há um lugar específico de resistência - então, em todos os lugares onde há relações de poder, há práticas de resistência, de modo que "[...] qualquer reação ou resistência contra uma relação de poder se dá sempre a partir de dentro das redes de poder num embate de forças" (RAGO; VEIGA-NETO, 2008, p. 48), e o palco que serve para estratégias múltiplas de resistência pode ser qualquer lugar da sociedade, como, por exemplo, o espaço escolar.

Embora Foucault (2015a) tenha dito que o poder está sempre "ali", que nunca estamos "fora" do poder, que não há margens para que isso aconteça, não significa dizer que se deva admitir uma forma absoluta de domínio. Afinal, para o autor, dizer que nunca se está fora do poder não significa que se está completamente capturado por suas armadilhas. No texto Poderes $e$ Estratégias - entrevista com Jacques Rancière -, que compõe a obra Ditos e Escritos IV, Foucault (2015a) refere-se às relações de poder e às práticas de resistência da seguinte forma:

Que não há relações de poder sem resistências; que estas são tão mais reais e eficazes quanto mais se formem ali mesmo onde se exercem as relações de poder; a resistência ao poder não tem que vir de fora para ser real, mas ela não é pega na armadilha porque ela é a compatriota do poder. Ela existe tanto mais quanto ela esteja ali onde está o poder; ela é, portanto, como ele, múltipla e integrável a estratégias globais. (FOUCAULT, 2015a, p. 244).

Práxis Educativa, Ponta Grossa, v. 12, n. 3, p. 772-787, set./dez. 2017 Disponível em: <http://www.revistas2.uepg.br/index.php/praxiseducativa $>$ 
Por isso, Foucault (1988) diz que “[...] lá onde há relações de poder há resistência e, no entanto, esta nunca se encontra em posição de exterioridade em relação ao poder" (FOUCAULT, 1988, p. 91). Ele continua dizendo que, "[...] para resistir, é preciso que a resistência seja como o poder. Tão inventiva, tão móvel, tão produtiva, quanto ele. Que, como ele, venha de 'baixo' e se distribua estrategicamente" (FOUCAULT, 2000, p. 241, grifo do autor). Em outras palavras, as práticas de resistência, na perspectiva foucaultiana, possuem as mesmas características que as relações de poder e não representam uma libertação em relação ao poder a partir de um lugar de exterioridade deste. Ao contrário, as práticas de resistência ocorrem ali mesmo onde há relações de poder - relações de poder e práticas de resistência são como as duas faces da mesma moeda. Assim sendo, não só as resistências podem fundar novas relações de poder, como novas relações de poder também podem dar origem a novas formas de resistência.

Se os dispositivos de saber/poder, ao mesmo tempo em que nos subjetivam, são o obstáculo contra o qual resistimos e reagimos, então, em nossas pesquisas, partimos da ideia de que, embora não seja possível escapar às relações de poder, podemos sempre e em toda parte modificá-las; "[...] porque o poder é uma relação bilateral; faz par com a obediência, que somos livres (sim, livres) de conceder com mais ou menos resistência" (VEYNE, 2009, p. 102). Contudo, também sabemos que os espaços de liberdade só têm a possibilidade de ultrapassar o dispositivo de saber/poder do momento presente.

h) Na mesma perspectiva, Nietzsche $(2008,1998)$ reforça que, mesmo na obediência, há resistência, que a vontade de potência nunca é neutralizada nem abolida. Entendendo a vida como vontade de potência, o filósofo afirma que, mesmo quando essa vontade é apenas reativa, negativa, ou quando expressa a vontade de nada, ou seja, quando é niilista, "[...] o homem preferirá querer o nada a nada querer" (NIETZSCHE, 1998, p. 149). Cada sujeito "[...] é o centro de uma energia que só pode ser vitoriosa ou vencida; no segundo caso, torna-se ressentimento ou, pelo contrário, fiel dedicação ao vencedor, ou as duas coisas ao mesmo tempo" (VEYNE, 2009, p. 102), mas é a vontade de potência que deseja, que impulsiona, que interpreta, que atribui sentido e significado ao mundo.

Nesse sentido, todo o conhecimento, inclusive o que produzimos em nossas pesquisas, não é a descoberta de algo que estava velado, mas é um ato de criação e invenção que nada tem de neutralidade e objetividade, pois é resultante da ação das forças que movem a vontade de potência. Cada pessoa, ao pensar, desejar e sentir, institui uma interpretação provisória de mundo que resulta de uma hierarquia de forças em disputa entre si, de vontades que atuam sobre vontades, expressando a provisoriedade, o movimento, o caráter dinâmico das diversas interpretações. Isso nos leva a pensar que o conhecimento não é a manifestação de uma essência anterior - originária de princípios metafísicos -, mas o resultado da ação criativa e inventiva do ser humano em constante luta por imposição de sentido. Isto é, as invenções não resultam de atos isolados de criação, "[...] elas estão em ação em um campo de forças, o que significa dizer que uma força age sobre outra força, que aquilo que as movimenta é a diferença entre uma força e outra" (CORAZZA; TADEU, 2003, p. 47), e é essa diferença que marca as diversas criações e invenções - ou aquilo que chamamos de verdade. Nesse caso, as perguntas que movem as nossas pesquisas não se referem a o que é; referem-se a o que faz com que seja o que é. Busca-se, "[...] antes, o impulso, o desejo, o motivo que faz com que as coisas tenham o sentido que têm do que sua essência, sua origem ou seu fundamento último" (CORAZZA; TADEU, 2003, p. 49).

i) Enquanto na tradição filosófica ocidental a linguagem é concebida de forma naturalizada e essencializada, como um mecanismo neutro e transparente capaz de representar fielmente a realidade, o Pós-estruturalismo, com base na concepção de linguagem de Saussure, concebe-a em constante movimento, em que os "[...] signos linguísticos operam de forma 
reflexiva e não de forma referencial: eles dependem da operação auto-reflexiva da diferença" (PETERS, 2000, p. 36). Assim, a linguagem já não é concebida como um vínculo neutro e transparente de representação da realidade, mas como parte integrante e fundamental de sua própria constituição. Os elementos da realidade social não são externos à linguagem, presos a uma ordem fixa, mas são considerados em termos semânticos, como discursos, significando um antirrealismo, "[...] uma posição epistemológica que se recusa a ver o conhecimento como uma representação precisa da realidade e se nega a conceber a verdade em termos de uma correspondência exata com a realidade" (PETERS, 2000, p. 37).

Autores como Michel Foucault, com a noção de "discurso", e Jaques Derrida, com a noção de "texto", muito contribuíram para destituir a linguagem de seu caráter naturalizado e essencializado. Em A Arqueologia do Saber, Foucault (2005) afirma que, mesmo que os discursos sejam constituídos de signos, "[...] o que fazem é mais que utilizar esses signos para designar coisas" (FOUCAULT, 2005, p. 55), agindo como práticas sociais em uma relação de saber/poder e produzindo a realidade. Na mesma perspectiva, em a Escritura e a Diferença, Derrida (1995) entende por discurso um "[...] sistema no qual o significado central, originário ou transcendental, nunca está absolutamente presente fora de um sistema de diferenças" (DERRIDA, 1995, p. 232). Ele diz que a linguagem não é redutível a uma metalinguagem unificadora; o que a caracteriza é o constante fluxo, a multiplicidade de linguagens, que não se deixam reduzir a um princípio unificador. Para o autor, foi dessa forma que a linguagem invadiu o campo problemático do universal e foi também o momento em que, "[...] na ausência de centro ou de origem - tudo se torna discurso - com a condição de nos entendermos sobre esta palavra - [...] sistema no qual o significado central, originário ou transcendental, nunca está absolutamente presente fora de um sistema de diferenças" (DERRIDA, 1995, p. 232). Ou seja, na ausência de significados transcendentais, o campo e o jogo da significação são ampliados indefinidamente.

j) Entender a linguagem como indeterminada e instável, como pensa Derrida (1995), reflete diretamente na questão das identidades e das diferenças dos sujeitos, pois, se as identidades e as diferenças são definidas, em certa medida, por meio da linguagem, também são marcadas pela indeterminação e pela instabilidade. Isso significa que sua definição - discursiva e linguística - está sujeita a vetores de força, a relações de poder. Por isso, pensamos com Deleuze (1988), Hall (2005) e Silva (2000), que as identidades e as diferenças dos sujeitos não são naturais, fixas e estáveis, esperando para serem reveladas, descobertas ou toleradas. Elas são construídas na história e na cultura por meio dos "atos de linguagem" que as nomeiam. Em outras palavras, as identidades e as diferenças não podem ser fixadas, determinadas, estabelecidas de uma vez por todas pelos sistemas discursivos e simbólicos, pois, como vimos com Derrida (1995), a "linguagem vacila".

Se as identidades e as diferenças são construídas nas relações sociais, em meio a campos hierárquicos - elas não convivem em harmonia, mas sim em constantes disputas. Então, quando em nossas pesquisas o propósito for fazer a análise de um discurso, não poderemos compreendêlo como um conjunto de signos, mas como práticas produtivas que possuem efeito de poder na fabricação das identidades e das diferenças dos sujeitos.

Os posicionamentos teórico-conceituais ou ferramentas analíticas fornecidas pela perspectiva pós-estruturalista - explicitados - indicam, mesmo que de forma provisória, caminhos da pesquisa e auxiliam-nos a manter certa vigilância epistemológica. Sabemos que as metodologias nesse campo teórico-metodológico são construídas/inventadas e podem ser re/significadas ao longo do processo de investigação. Então, mesmo tomando os conceitos como centrais no processo de pesquisa, sabemos que eles não são naturais e eternos, fixos e estáveis. Eles são criados dentro de determinados contextos a fim de tornar a "realidade" compreensível. 
Dessa forma, precisamos ficar atentos para não nos tornarmos prisioneiros também desses conceitos ou ferramentas analíticas que apresentamos.

Quando Deleuze e Guattari (2004) afirmam que a filosofia é a arte de formar, de inventar, de fabricar conceitos, estão justamente criticando os filósofos que preferiram considerar o conceito como um conhecimento ou uma representação já dada e afirmam que "[...] o conceito não é dado, é criado, está por criar; não é formado, ele próprio se põe em si mesmo, autoposição" (DELEUZE; GUATTARI, 2004, p. 20). Esses autores ressaltam que a filosofia perdeu de vista que os conceitos são construções históricas, pois, à medida que os construía, passou a acreditar neles e a naturalizá-los. Em vez de contemplar as ideias, como pretendia Platão, Deleuze e Guattari (2004) lembram que foi necessário, antes, que Platão tivesse criado o conceito de ideia.

Trata-se de compreender que os conceitos apresentados, ou os conceitos que utilizamos em nossas pesquisas, dizem sobre os acontecimentos, não sobre a essência ou as coisas. Os conceitos não são uma representação universal da realidade; eles se voltam sobre a concreticidade dos fatos, dos acontecimentos, da realidade, re/significando e transformando o mundo. Dito de outro modo, não podemos ter uma compreensão idealista dos conceitos como se fossem ideias que representam a realidade, pois "[...] o conceito é sempre uma intervenção no mundo, seja para conservá-lo seja para mudá-lo" (GALLO, 2008, p. 36). O conceito, para ter significado, precisa remeter-se a outros conceitos, considerando sempre a história do conceito e as relações com o contexto presente.

Ainda precisamos considerar, com Gallo (2008), que, ao mesmo tempo que o conceito é produzido a partir de determinadas condições, ele também é produtor de novos pensamentos, de novos conceitos, pois o conceito recorta o acontecimento e o torna possível. Por isso, os conceitos são entendidos em nossas pesquisas como "[...] uma aventura do pensamento que institui um acontecimento, vários acontecimentos, que permite um ponto de visada sobre o mundo, sobre o vivido" (GALLO, 2008, p. 38). Não basta posicionar-se passivamente frente aos conceitos criados ao longo da história. É preciso saber avaliar "[...] a novidade histórica dos conceitos criados [...] a potência de seu devir quando eles passam uns pelos outros" (DELEUZE; GUATTARI, 2004, p. 46), pois "[...] aqueles que criticam sem criar, aqueles que se contentam em defender o que se esvaneceu sem saber dar-lhes forças para retornar à vida [...]” (DELEUZE; GUATTARI, 2004, p. 42) fazem simplesmente generalizações vazias.

Assim, entendemos os conceitos que utilizamos em nossas pesquisas como movediços, porque históricos. Cabe ao pesquisador esclarecer o sentido que dá a cada palavra, “[...] construindo os contextos e estabelecendo os elos denotativos e conotativos, num processo inesgotável, porque infinito, de afinação e abrangência" (VEIGA-NETO, 2002, p. 38), transformando os conceitos interessantes para a pesquisa.

Desse modo, pensamos que uma das contribuições da perspectiva pós-estruturalista, como abordagem epistemológica para a pesquisa em educação, consiste na leitura desconstrutora das categorias essencializadas e naturalizadas da modernidade. Os teóricos de viés pósestruturalista, ao não considerarem os conceitos/as verdades da racionalidade moderna ocidental como a priori histórico - pelo contrário, o a priori é deslocado para a história -, fazem-nos ver que as metanarrativas modernas derivam dos próprios arranjos históricos que engendraram o pensamento de uma época. Assim, potencializam nossas pesquisas em educação para saírem constantemente do traçado prévio, do caminho estabelecido, dos conceitos dados; por conseguinte, abrem espaços para as re/significações dos processos educativos, tão importantes para as instituições educacionais.

Práxis Educativa, Ponta Grossa, v. 12, n. 3, p. 772-787, set./dez. 2017 Disponível em: <http://www.revistas2.uepg.br/index.php/praxiseducativa $>$ 
A produção do conhecimento em educação: o Pós-estruturalismo como potência epistemológica

\section{Algumas considerações}

Essas são algumas das re/significações conceituais que buscamos no Pós-estruturalismo e que consideramos importantes quando assumimos essa perspectiva epistemológica e metodológica para nossas pesquisas. Elas têm possibilitado ver, buscar, encontrar outros caminhos, outras possibilidades metodológicas que, de certo modo, transgridem as metodologias e os procedimentos que até então tínhamos como dados a priori, portanto, fixos e estáveis.

Dizemos isso porque a perspectiva pós-estruturalista na pesquisa em educação possibilita desconstruir a herança das filosofias clássica e moderna, que tanto têm marcado e ainda marcam os processos educacionais; possibilita desconstruir as unidades puras, claras e distintas para fazer ver, nos contextos educacionais, a impureza das multiplicidades e a imprevisibilidade que as caracteriza; possibilita entender que aquilo que chamamos de verdade não diz sobre a essência das coisas e expressa simplesmente nossa vontade de verdade, pois a verdade só existe em uma relação de poder, e o poder sempre opera em conexão com a verdade - então, as coisas não têm essência, os sujeitos de nossas pesquisas não possuem uma identidade essencial -; possibilita desconstruir a transparência da linguagem, do discurso, e deixa ver os regimes de verdade que circulam nas instituições educacionais e que se fazem em meio a um jogo de forças em constante disputa; possibilita desconstruir a ideia de um poder opressor e "mau" por natureza, para ver as relações de poder e as práticas de resistência como produtivas, agindo na constituição e na condução das subjetividades nos contextos educacionais; possibilita desconstruir a ideia de linearidade dos fatos, dos acontecimentos, da história, para poder ver as descontinuidades que ocorrem a todo o momento - não que se trate de negar ou abandonar as continuidades, mas de fazer ver que, nos espaços educacionais, há momentos de ruptura nos discursos, momentos estes produzidos por variadas práticas institucionais e relações de poder -; possibilita desconstruir a ideia de um sujeito soberano, de um sujeito constituinte do saber, para entendê-lo como constituído na dispersão e na empiricidade dos acontecimentos; possibilita forçar o pensamento a sair da lógica das oposições binárias para poder ver que os sujeitos de nossas pesquisas não são somente sujeitos sujeitados, são, também, e ao mesmo tempo, produtivos, criativos, inventivos.

Desse modo, o Pós-estruturalismo, como perspectiva epistemológica e metodológica, tem nos lembrado constantemente de que podemos sair do aprisionamento, da fixidez, do essencialismo metodológico, e tem nos mobilizado a buscar, a encontrar novos modos de fazer pesquisa em educação. Já é possível suspeitar das práticas e dos saberes instituídos e dos sentidos produzidos pelos conceitos fixos e estáveis; já é possível desnaturalizar o que se apresenta como natural e absoluto e estranhar o que se apresenta como familiar e normal. Para dizer de outra forma, a pesquisa nessa perspectiva faz-nos trilhar caminhos diferentes dos estabelecidos, faz-nos resistir a práticas e saberes que se colocam como permanentes, a sentidos que se apresentam como fixos, a tempos e espaços que parecem lineares demais.

No entanto, não podemos esperar que esse posicionamento epistemológico traga mais tranquilidade para nossas pesquisas; pelo contrário, faz surgir novos questionamentos, novas dificuldades, novos desafios, mas possibilita "[...] liberar o pensamento daquilo que ele pensa silenciosamente, e permitir-lhe pensar diferentemente" (FOUCAULT, 1998, p. 14). Outras leituras, outras interpretações, outras interrogações, outros movimentos mostram a infinidade de possibilidades de fazer-se pesquisa em educação - já é possível ir além dos universalismos e essencialismos.

Nossas pesquisas em educação serão mais multiplicadoras de inquietações e problematizações, mais instigadoras e estimuladoras de pensamentos e ações do que preocupadas em buscar respostas totais e universais para os problemas educacionais. Assim, a potencialidade

Práxis Educativa, Ponta Grossa, v. 12, n. 3, p. 772-787, set./dez. 2017 Disponível em: < http://www.revistas2.uepg.br/index.php/praxiseducativa > 
dessa perspectiva epistemológica e metodológica para a pesquisa em educação está na multiplicidade de possibilidades que ela proporciona.

\section{Referências}

BENNINGTON, G.; DERRIDA, J. Jaques Derrida. Rio de Janeiro: Jorge Zahar, 1996.

CANDIOTTO, C. Foucault e a crítica da verdade. Belo Horizonte: Autêntica, 2010.

COLLING, A. M. Tempos diferentes discursos iguais: a construção histórica do corpo feminino. Dourados: UFGD, 2014.

CORAZZA, S.; TADEU, T. Composições. Belo Horizonte: Autêntica, 2003.

DELEUZE, G. Nietzsche e a filosofia. Rio de Janeiro: Rio, 1976.

DELEUZE, G. Diferença e repetição. Rio de Janeiro: Graal, 1988.

DELEUZE, G.; GUATTARI, F. O que é a filosofia. Rio de Janeiro: 34, 2004.

DERRIDA, J. A escritura e a diferença. 2. ed. São Paulo: Perspectiva, 1995.

DERRIDA, J.; ROUDINESCO, E. De que amanhã... Diálogo. Rio de Janeiro: Jorge Zahar, 2004.

DREYFUS, H. L.; RABINOW, P. Michel Foucault: Uma trajetória filosófica - para além do estruturalismo e da hermenêutica. 2. ed. Rio de Janeiro: Forense Universitária, 2013.

FISCHER, R. M. B. Foucault e a análise do discurso em educação. Cadernos de Pesquisa, São Paulo, n. 114, p. 197-223, nov. 2001. DOI: 10.1590/S0100-15742001000300009

FONSECA, M. A. Michel Foucault e a constituição do sujeito. 2. ed. São Paulo: EDUC, 2011.

FOUCAULT, M. História da sexualidade: a vontade de saber. 13. ed. Rio de Janeiro: Graal, 1988.

FOUCAULT, M. Vigiar e punir. 14. ed. Petrópolis: Vozes, 1996 a.

FOUCAUlT, M. A ordem do discurso. São Paulo: Loyola, 1996b.

FOUCAULT, M. História da sexualidade: o uso dos prazeres. 8. ed. Rio de Janeiro: Graal, 1998.

FOUCAULT, M. Em defesa da sociedade. São Paulo: Martins Fontes, 1999.

FOUCAULT, M. Microfísica do poder. 15. ed. Rio de Janeiro: Graal, 2000.

FOUCAULT, M. A verdade e as formas jurídicas. 3. ed. Rio de Janeiro: Nau, 2002. 
A produção do conhecimento em educação: o Pós-estruturalismo como potência epistemológica

FOUCAULT, M. A hermenêutica do sujeito. São Paulo: Martins Fontes, 2004.

FOUCAULT, M. A arqueologia do saber. 7. ed. Rio de Janeiro: Forense Universitária, 2005.

FOUCAULT, M. Poderes e estratégias. In: FOUCAULT, M. Ditos e Escritos IV: Estratégia, poder-saber. 3. ed. Rio de Janeiro: Forense Universitária, 2015a. p. 236-246.

FOUCAULT, M. Sobre a arqueologia das ciências: resposta ao círculo de epistemologia. In: FOUCAULT, M. Ditos e Escritos II: Arqueologia das ciências e história dos sistemas de pensamento. 3. ed. Rio de Janeiro: Forense Universitária, 2015b. p. 85-123.

GALLO, S. Deleuze e a educação. 2. ed. Belo Horizonte: Autêntica, 2008.

HALL, S. A identidade cultural na pós-modernidade. 10. ed. Rio de Janeiro: DP\&A, 2005.

LARROSA, J. Tecnologias do Eu e Educação. In: SILVA, T. T. (Org.). O sujeito da educação: estudos foucaultianos. 8. ed. Petrópolis: Vozes, 2011. p. 35-86.

MEYER, D. E. Abordagens pós-estruturalistas de pesquisa na interface educação, saúde e gênero: perspectiva metodológica. In: MEYER, D. E.; PARAÍSO, M. A. (Orgs.). Metodologias de pesquisas pós-críticas em educação. Belo Horizonte: Mazza, 2012. p. 47-61.

NIETZSCHE, F. Genealogia da moral. São Paulo: Companhia das Letras, 1998.

NIETZCHE, F. A vontade de poder. Rio de Janeiro: Contraponto, 2008.

PARAÍSO, M. A. Metodologias de pesquisa pós-críticas em educação: trajetória, pressupostos, procedimentos e estratégias analíticas. In: MEYER, D. E.; PARAÍSO, M. A. (Orgs.). Metodologias de pesquisas pós-críticas em educação. Belo Horizonte: Mazza, 2012. p. 2345.

PETERS, M. Pós-estruturalismo e filosofia da diferença: uma introdução. Belo Horizonte: Autêntica, 2000.

PIMENTA, O. Razão e conhecimento em Descartes e Nietzsche. Belo Horizonte: UFMG, 2000.

RAGO, M.; VEIGA-NETO, A. (Orgs.). Figuras de Foucault. 2. ed. Belo Horizonte: Autêntica, 2008.

SANTIAGO, S. Arte masculina? In: NOLASCO, S. A desconstrução do masculino. Rio de Janeiro: Rocco, 1995. p. 99-102.

SILVA, T. T. A produção social da identidade e da diferença. In: SILVA, T. T. (Org.). Identidade e diferença: a perspectiva dos Estudos Culturais. Rio de Janeiro: Vozes, 2000. p. 73 102.

VEIGA-NETO, A. Coisas de governo. In: RAGO, M.; ORLANDI L. B. L.; VEIGA-NETO, A. (Orgs.). Imagens de Foucault e Deleuze: ressonâncias nietzschianas. Rio de Janeiro: DP\&A, 2002. p. $13-34$. 
VEIGA-NETO, A. Foucault e a educação. Belo Horizonte: Autêntica, 2003.

VEYNE, P. Foucault o pensamento a pessoa. Lisboa: Texto e Grafia, 2009.

Recebido em 17/10/2016

Versão corrigida recebida em 23/02/2017

Aceito em 26/02/2017 